\title{
Metadata describing the Kharaa Yeröö River Basin Water Quality Database
}

Jürgen Hofmann (1D), Ralf Ibisch, Daniel Karthe (D), Buren Scharaw, Michael Schäffer, Melanie Hartwig, Philipp Theuring (D), Michael Rode, Saulyegul Avlyush (1D, Vanessa Watson, Vanessa Bremerich , Gerel Osor, Andrew Kaus (1D, Katja Westphal, Martin Pfeiffer (D), Jörg Priess (D), Christian Schweitzer, Daniel Krätz, Jonas Gröning (iD, Jens Hürdler, Gunsmaa Batbayar (D), Sonja Heldt, Olaf Büttner (D) \& Dietrich Borchardt (iD)

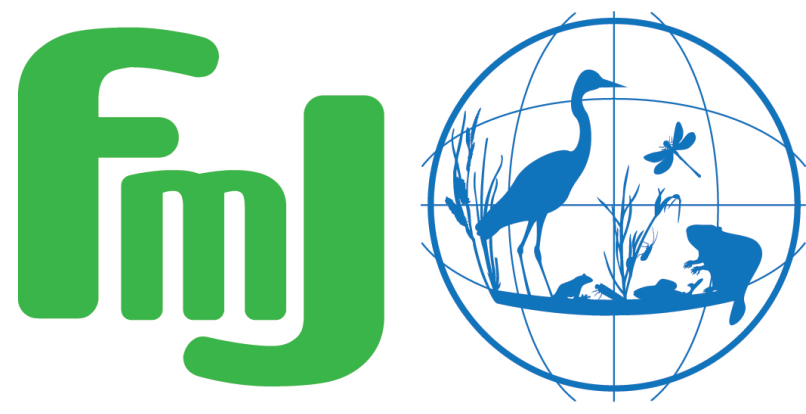

Freshwater Metadata Journal 



\title{
Metadata describing the Kharaa Yeröö River Basin Water Quality Database
}

\author{
Jürgen Hofmann ${ }^{1}$ (iD), Ralf Ibisch ${ }^{4}$, Daniel Karthe ${ }^{7}$ (iD), Buren Scharaw ${ }^{5}$, Michael Schäffer \\ 4, Melanie Hartwig ${ }^{4}$, Philipp Theuring ${ }^{4}$ (iD , Michael Rode ${ }^{3}$, Saulyegul Avlyush ${ }^{9}$ (D) , \\ Vanessa Watson ${ }^{6}$, Vanessa Bremerich ${ }^{1}$ (D), Gerel Osor ${ }^{8}$, Andrew Kaus ${ }^{4}$ iD, Katja \\ Westphal ${ }^{3}$, Martin Pfeiffer $^{3}$ (iD , Jörg Priess ${ }^{3}$ (iD , Christian Schweitzer ${ }^{4}$, Daniel Krätz ${ }^{4}$, \\ Jonas Gröning ${ }^{1}$ (D) , Jens Hürdler ${ }^{2}$, Gunsmaa Batbayar ${ }^{7}$ (D) , Sonja Heldt ${ }^{10}$, Olaf Büttner ${ }^{3}$ \\ \& Dietrich Borchardt ${ }^{3}$
}

\footnotetext{
1 Leibniz-Institute of Freshwater Ecology and Inland Fisheries (IGB), Berlin, Germany; corresponding author: j.hofmann@igb-berlin.de 2 formerly: Leibniz-Institute of Freshwater Ecology and Inland Fisheries (IGB), Berlin, Germany

3 Helmholtz-Centre for Environmental Research (UFZ), Magdeburg, Leipzig, Germany

4 formerly: Helmholtz-Centre for Environmental Research (UFZ), Magdeburg, Leipzig, Germany

5 Advanced System Technology (AST) Branch of Fraunhofer IOSB, IImenau, Germany

6 formerly: Advanced System Technology (AST) Branch of Fraunhofer IOSB, Ilmenau, Germany

7 German-Mongolian Institute for Resources and Technology (GMIT), Nalaikh, Mongolia

8 formerly: Mongolian University of Science and Technology (MUST), Darkhan, Mongolia

9 Institute of Geography and Geoecology (IGG), Mongolian Academy of Sciences (MAS), Ulaanbaatar, Mongolia

10 formerly: University of Duisburg-Essen (UDE), Essen, Germany
}

Please cite this paper as follows: Hofmann, J., Ibisch, R., Karthe, D., Scharaw, B., Schäffer, M., Hartwig, M., Theuring, P., Rode, M., Avlyush, S., Watson, V., Bremerich, V., Osor, G., Kaus, A., Westphal, K., Pfeiffer, M., Priess, J., Schweitzer, C., Krätz, D., Gröning, J., Hürdler, J., Batbayar, G., Heldt, S., Büttner, O. \& Borchardt, D., 2018. Metadata describing the Kharaa Yeröö River Basin Water Quality Database. Freshwater Metadata Journal 36: 1-10. https://doi.org/10.15504/fmj.2018.36

Received: 2018-08-20 / Published: 2018-09-28

\section{Keywords}

river, fluvial sediments, freshwater systems, nutrients, heavy metals, metalloids, groundwater, environmental monitoring, water chemistry, pollution

\section{Short description of the dataset/summary}

In the framework of the BMBF funded project on Integrated Water Resources Management in Central Asia (Model region Mongolia, MOMO project, www.iwrm-momo.de) the objectives focused on supplementing, validating and extending the existing surveillance monitoring to the entire river basin for the time series 2006-2017.

The MOMO monitoring programme was set up in order to observe seasonal variation in various water quality parameters along the main river course and its tributaries. A detailed sampling survey was carried out along the Kharaa River in the spring, summer and autumn of 2006 to 2017, extending from the headwaters in the Khentii Mountains to the outlet of the river basin. An additional continuous monthly monitoring programme for surface water quality was carried out 
upstream (Deed Guur) and downstream of Darkhan city (Buren Tolgoi) including the outlet of WWTP Darkhan in the time between 2007 and 2017.

This strategy provides information for the efficient and effective design of future monitoring programmes with a focus on operational or investigative issues. The types of water sampling programmes included initial surveys as well as investigative and operational monitoring, point-source characterization, intensive surveys, fixed-station-network monitoring, groundwater monitoring, and special surveys involving chemical and biological monitoring. The water analyses have a focus on nutrients, heavy metals and metalloids, chloride, boron and the main physical water parameters. The dataset comprises also fluvial sediment analyses on heavy metals. In addition in 2017 a special hygienic monitoring (total coliforms, E. coli and fecal coliforms) has been carried out and was included in this database.

\section{General information}

\begin{tabular}{|c|c|}
\hline \multirow{2}{*}{\multicolumn{2}{|c|}{$\begin{array}{l}\text { dataset entry ID: } \\
\text { name of the dataset: }\end{array}$}} \\
\hline & \\
\hline full name of the dataset: & Kharaa Yeröö River Basin Water Quality Database \\
\hline dataset short name: & MoMo Water Quality Database \\
\hline type of dataset: & environmental characteristics database \\
\hline data type: & point data/observation data \\
\hline \multicolumn{2}{|c|}{ science keywords according to GCMD: } \\
\hline topic: & Terrestrial Hydrosphere \\
\hline \multicolumn{2}{|c|}{ ISO topic category according to ISO 19115: } \\
\hline & Environment, Inland Waters \\
\hline \multicolumn{2}{|c|}{ INSPIRE keywords according to GEMET: } \\
\hline own science keywords: & $\begin{array}{l}\text { Environmental monitoring facilities } \\
\text { river, fluvial sediments, freshwater systems, nutrients, heavy metals, metalloids, } \\
\text { groundwater, water chemistry, pollution }\end{array}$ \\
\hline related project: & $\begin{array}{l}\text { Integrated Water Resources Management (IWRM) in Central Asia: Model } \\
\text { Region Mongolia (MoMo) }\end{array}$ \\
\hline funding: & $\begin{array}{l}\text { German Federal Ministry of Education and Research (BMBF project No. } \\
033 \text { W016DN) }\end{array}$ \\
\hline
\end{tabular}

\section{Technical and administrative specifications}

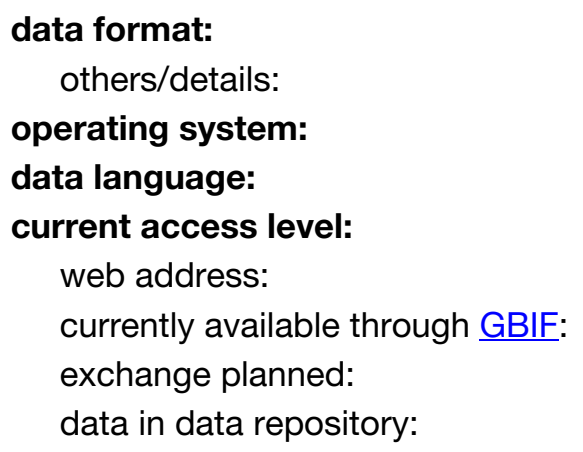

Access

PostgreSQL

all Windows systems

English

web (public)

https://nimbus.igb-berlin.de/index.php/s/Wi0Fd78izfydYY2

\section{no}

no

no

Do you plan to publish the data on the Freshwater Biodiversity Data Portal:

update level:

documentation:

type:

language: no

completed, update planned

manual

English 


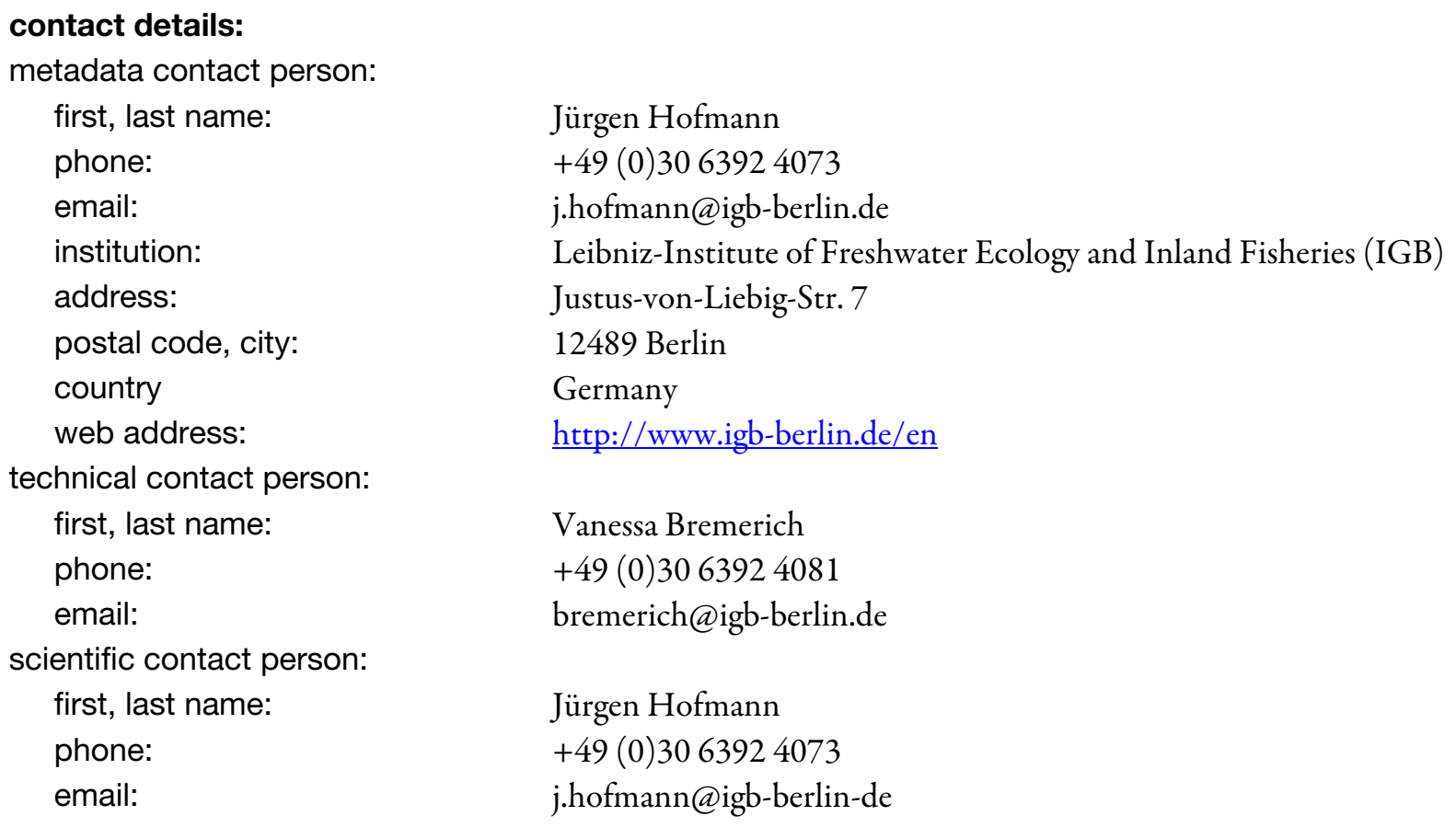

\section{Intellectual property rights and citation}

\section{dataset publisher: \\ dataset creator (data compiler):}

contact name:

contact email:

contact institution:
MoMo consortium

Jürgen Hofmann

j.hofmann@igb-berlin.de

Leibniz-Institute of Freshwater Ecology and Inland Fisheries (IGB)

data contributors to/owners of this dataset:

multiple

number:

24

\section{data contributor/owner 1:}

contact name:

contact email:

Jürgen Hofmann

contact institute:

j.hofmann@igb-berlin.de

Leibniz-Institute of Freshwater Ecology and Inland Fisheries (IGB)

criteria for using this part of the dataset:

The dataset is publicly available (data portal, data archive) and can be used without restrictions, but must be acknowledged and cited correctly.

\section{data contributor/owner 2:}

contact name:

contact email:

Ralf Ibisch

contact institute:

ralf.ibisch@gmx.de

formerly: Helmholtz-Centre for Environmental Research (UFZ)

criteria for using this part of the dataset:

The dataset is publicly available (data portal, data archive) and can be used without restrictions, but must be acknowledged and cited correctly.

\section{data contributor/owner 3:}

contact name:

contact email:

contact institute:
Daniel Karthe

karthe@gmit.edu.mn

German-Mongolian Institute for Resources and Technology (GMIT) 
criteria for using this part of the dataset:

The dataset is publicly available (data portal, data archive) and can be used without restrictions, but must be acknowledged and cited correctly.

data contributor/owner 4:
contact name:
Buren Scharaw
contact email:
buren.scharaw@iosb-ast.fraunhofer.de
contact institute:
Advanced System Technology (AST) Branch of Fraunhofer IOSB

criteria for using this part of the dataset:

The dataset is publicly available (data portal, data archive) and can be used without restrictions, but must be acknowledged and cited correctly.

data contributor/owner 5:
contact name:
Michael Schäffer
contact email:
schaeffer@bafg.de
contact institute:
formerly: Helmholtz-Centre for Environmental Research (UFZ)

criteria for using this part of the dataset:

The dataset is publicly available (data portal, data archive) and can be used without restrictions, but must be acknowledged and cited correctly.

data contributor/owner 6:
contact name:
Melanie Hartwig
contact email:
MelanieHartwig@gmx.de
contact institute:
formerly: Helmholtz-Centre for Environmental Research (UFZ)

criteria for using this part of the dataset:

The dataset is publicly available (data portal, data archive) and can be used without restrictions, but must be acknowledged and cited correctly.

data contributor/owner 7:
contact name:
Philipp Theuring
contact email:
theuring@seba.de
contact institute:
formerly: Helmholtz-Centre for Environmental Research (UFZ)
criteria for using this part of the dataset:

The dataset is publicly available (data portal, data archive) and can be used without restrictions, but must be acknowledged and cited correctly.

data contributor/owner 8:

contact name:

Michael Rode

contact email:

michael.rode@ufz.de

contact institute:

criteria for using this part of the dataset:

Helmholtz-Centre for Environmental Research (UFZ)

The dataset is publicly available (data portal, data archive) and can be used without restrictions, but must be acknowledged and cited correctly.

data contributor/owner 9:

contact name:

contact email:

contact institute:

Saulyegul Avlyush

saulegul_a@daad-alumni.de

Institute of Geography and Geoecology (IGG), Mongolian Academy of Sciences (MAS)

criteria for using this part of the dataset:

The dataset is publicly available (data portal, data archive) and can be used without restrictions, but must be acknowledged and cited correctly.

\section{data contributor/owner 10:}

contact name:

contact email:

contact institute:
Vanessa Watson

vanessa.watson@iosb-ast.fraunhofer.de

formerly: Advanced System Technology (AST) Branch of Fraunhofer IOSB 
criteria for using this part of the dataset:

The dataset is publicly available (data portal, data archive) and can be used without restrictions, but must be acknowledged and cited correctly.

data contributor/owner 11:

contact name:

Vanessa Bremerich

contact email:

bremerich@igb-berlin.de

contact institute:

criteria for using this part of the dataset:

Leibniz-Institute of Freshwater Ecology and Inland Fisheries (IGB)

The dataset is publicly available (data portal, data archive) and can be used without restrictions, but must be acknowledged and cited correctly.

data contributor/owner 12:

contact name:

Gerel Osor

contact email:

contact institute:

criteria for using this part of the dataset:

formerly: Mongolian University of Science and Technology (MUST)

The dataset is publicly available (data portal, data archive) and can be used without restrictions, but must be acknowledged and cited correctly.

data contributor/owner 13:

contact name:

Andrew Kaus

contact email:

andrewkinglseykaus@gmail.com

contact institute:

formerly: Helmholtz-Centre for Environmental Research (UFZ)

criteria for using this part of the dataset:

The dataset is publicly available (data portal, data archive) and can be used without restrictions, but must be acknowledged and cited correctly.

data contributor/owner 14:

contact name:

Katja Westphal

contact email:

katja.westphal@ufz.de

contact institute:

Helmholtz-Centre for Environmental Research (UFZ)

criteria for using this part of the dataset:

The dataset is publicly available (data portal, data archive) and can be used without restrictions, but must be acknowledged and cited correctly.

data contributor/owner 15:

contact name:

Martin Pfeiffer

contact email:

martin.pfeiffer@ufz.de

contact institute:

Helmholtz-Centre for Environmental Research (UFZ)

criteria for using this part of the dataset:

The dataset is publicly available (data portal, data archive) and can be used without restrictions, but must be acknowledged and cited correctly.

data contributor/owner 16:

contact name:

contact email:

Jörg Priess

contact institute:

joerg.priess@ufz.de

Helmholtz-Centre for Environmental Research (UFZ)

criteria for using this part of the dataset:

The dataset is publicly available (data portal, data archive) and can be used without restrictions, but must be acknowledged and cited correctly.

data contributor/owner 17:

contact name:

Christian Schweitzer

contact email:

christian.schweitzer@uba.de

contact institute:

formerly: Helmholtz-Centre for Environmental Research (UFZ)

criteria for using this part of the dataset:

The dataset is publicly available (data portal, data archive) and can be used 


\section{data contributor/owner 18:}

contact name:

contact email:

without restrictions, but must be acknowledged and cited correctly.

contact institute:

Daniel Krätz

danielkraetz@gmx.de

criteria for using this part of the dataset:

The dataset is publicly available (data portal, data archive) and can be used without restrictions, but must be acknowledged and cited correctly.

\section{data contributor/owner 19:}

contact name:

contact email:

Jonas Gröning

contact institute:

groening@igb-berlin.de

criteria for using this part of the dataset:

The dataset is publicly available (data portal, data archive) and can be used without restrictions, but must be acknowledged and cited correctly.

data contributor/owner 20:

contact name:

contact email:

Jens Hürdler

contact institute:

jens.huerdler@googlemail.com

criteria for using this part of the dataset:

The dataset is publicly available (data portal, data archive) and can be used without restrictions, but must be acknowledged and cited correctly.

\section{data contributor/owner 21:}
contact name:
Gunsmaa Batbayar
contact email:
gunsmaa@gmit.edu.mn
contact institute:
German-Mongolian Institute for Resources and Technology (GMIT)

criteria for using this part of the dataset:

The dataset is publicly available (data portal, data archive) and can be used without restrictions, but must be acknowledged and cited correctly.

\section{data contributor/owner 22:}
contact name:
Sonja Heldt
contact email:
heldt.sonja@eglv.de
contact institute:
formerly: University of Duisburg-Essen (UDE)

criteria for using this part of the dataset:

The dataset is publicly available (data portal, data archive) and can be used without restrictions, but must be acknowledged and cited correctly.

\section{data contributor/owner 23:}
contact name:
Olaf Büttner
contact email:
olaf.buettner@ufz.de
contact institute:
Helmholtz-Centre for Environmental Research (UFZ)

criteria for using this part of the dataset:

The dataset is publicly available (data portal, data archive) and can be used without restrictions, but must be acknowledged and cited correctly.

\section{data contributor/owner 24:}
contact name:
Dietrich Borchardt
contact email:
dietrich.borchardt@ufz.de
contact institute:
criteria for using this part of the dataset:
Helmholtz-Centre for Environmental Research (UFZ)

The dataset is publicly available (data portal, data archive) and can be used without restrictions, but must be acknowledged and cited correctly. 


\section{citation of this dataset:}

author(s):

title and journal (name, number, pages):

Kharaa Yeröö River Basin Water Quality Database.

year:

citation of the metadata:

author(s):

title and journal (name, number, pages):

Hofmann J., Ibisch R., Karthe D., Scharaw B., Schäffer M., Hartwig M.,

Theuring P., Rode M., Avlyush S., Watson V., Bremerich V., Osor G., Kaus A.,

Westphal K., Pfeiffer M., Priess J., Schweitzer C., Krätz D., Gröning J., Hürdler J., Batbayar G., Heldt S., Büttner O. \& Borchardt D.

Metadata describing the Kharaa Yeröö River Basin Water Quality Database.

Freshwater Metadata Journal 36: 1-10

year:

2018

doi:

dataset related references:

reference 1:

author(s):

title:

year:

doi:

reference 2:

author(s):

title:

year:

doi:

reference 3:

author(s):

title:

year:

doi:

reference 4:

author(s):

title:

year:

doi:

reference 5:

author(s):
Batbayar, G., Pfeiffer, M., von Tümpling, W., Kappas, M. \& Karthe, D. Chemical water quality gradients of the sub catchments of the Mongolian Selenga River basin. Environmental Monitoring and Assessment 189: 420. 2017

https://doi.org/10.1007/s10661-017-6123-z

Hofmann, J., Watson, V. \& Scharaw, B.

Groundwater quality under stress: contaminants in the Kharaa River basin (Mongolia). Environmental Earth Sciences 73(2): 629-648.

2015

https://doi.org/10.1007/s12665-014-3148-2

Pfeiffer, M., Batbayar, G., Hofmann, J., Siegfried, K., Karthe, D. \&

Hahn-Tomer, $S$.

Investigating arsenic (As) occurrence and sources in ground, surface, waste and drinking water in northern Mongolia. Environmental Earth Sciences 73(2):

649-662.

2015

https://doi.org/0.1007/s12665-013-3029-0

Kaus, A., Schäffer, M., Karthe, D., Büttner, O., von Tümpling, W. \& Borchardt, D.

Regional patterns of heavy metal concentrations in water, sediment and five consumed fish species of the Kharaa River basin, Mongolia. Regional Environmental Change 17(7): 2023-2037.

2017

https://doi.org/10.1007/s10113-016-0969-4

Hofmann, J., Karthe, D., Ibisch, R., Schäffer, M., Kaus, A., Avlyush, S. \& Heldt, S. https://doi.org/10.15504/fmj.2018.36 
title:

year:

doi:
Initial characterization and water quality assessment of stream landscapes in Northern Mongolia and its integration into a River Basin Management Plan. Water 7(7): 3166-3205.

2015

https://doi.org/10.3390/w7073166

\section{General data specifications}

regional coverage of the dataset: spatial extent of the dataset: catchment continents:

Asia

spatial extent (bounding coordinates):

southernmost latitude $\left[{ }^{\circ}\right]$ :

46.8761

northernmost latitude $\left[^{\circ}\right]$ :

50.2525

westernmost longitude $\left[{ }^{\circ}\right]$ :

102.1911

easternmost longitude $\left[{ }^{\circ}\right]$ :

107.4601

minimum altitude:

599 metres

maximum altitude:

1478 metres

countries:

Asia: Mongolia

world climatic regions according to Köppen:

Group B: dry (arid and semiarid) climates

Group D: continental/microthermal climate

freshwater ecoregions of the world (FEOW) according to WWF:

ecosystem type:

covered timeframe:
Asia: Lake Baikal

rivers, lakes/ponds, groundwater, general freshwater

$2006-2017$

\section{Site specifications}

$\begin{array}{ll}\text { coordinate system/grid data: } & \text { latitude/longitude, format: DD } \\ \text { datum (e.g. WGS84): } & \text { WGS84 } \\ \text { grid data available: } & \text { no } \\ \text { site coding: } & \\ \text { site coding available: } & \text { yes, alphanumerical } \\ \text { number of digits: } & 12 \\ \text { example: } & \text { Sel_Kh01_001 } \\ \text { number of sites: } & 100-1000 \\ \text { exact number of sites: } & 246\end{array}$

\section{Climate and environmental data}

climate related data:

no climate data available

spatial resolution of the data (if not catchment/site related):

comments:

others/specify

The Kharaa Yeröö River basin belongs partly to cold semi-arid climates (BSk) and sub-alpine/boreal climate (Dwc) according to the KÖPPEN classification scheme.

environmental data: 
physico-chemical data:

other physico-chemical parameters:

no environmental data per catchment available

no environmental data per site avaiable

total $\mathrm{P}$, nitrate, nitrite, total $\mathrm{N}$, ammonium, sulphate, chloride, sodium, magnesium, labile aluminium, calcium, TOC (total organic carbon), water temperature, $\mathrm{pH}$, conductivity, suspended solids

air temperature, antimony, arsenic, barium, beryllium, bismuth, boron, bromide, cadmium, chromium, chromium(VI), cobalt, copper, cyanide, diphosphorus pentoxide, dissolved inorganic carbon, dissolved inorganic nitrogen, dissolved nitrogen, dissolved organic carbon, dissolved organic nitrogen, Eschericha coli, fecal coliforms, fluoride, iron, lead, lithium, manganese, mercury, molybdenum, nickel, organic matter in suspended solids, oxygen concentration, oxygen saturation, phosphate, potassium, rubidium, silicic acid, silver, soluble reactive phosphorus, strontium, thallium, tin, titanium, total dissolved solids, total hardness, total coliforms, turbidity, uranium, vanadium, water quality index, zinc

availability of physico-chemical data, if there is more than one sample per site: per sample

stressors influencing the sites:

reference sites available:

yes

\begin{tabular}{|l|l|l|l|l|}
\hline stressor & $\begin{array}{l}\text { restored sites } \\
\text { available }\end{array}$ & $\begin{array}{l}\text { data before/after } \\
\text { restoration } \\
\text { available }\end{array}$ & $\begin{array}{l}\text { stressor gradient } \\
\text { available }\end{array}$ & comments \\
\hline eutrophication & no & no & yes \\
\hline $\begin{array}{l}\text { hydromorphological } \\
\text { degradation }\end{array}$ & no & no & yes & \\
\hline organic pollution & no & no & no & no \\
\hline toxic stress & no & no & yes \\
\hline general degradation & no & yes & \\
\hline
\end{tabular}

\section{Other specifications}

\section{GIS layers, shape files related to the dataset:}

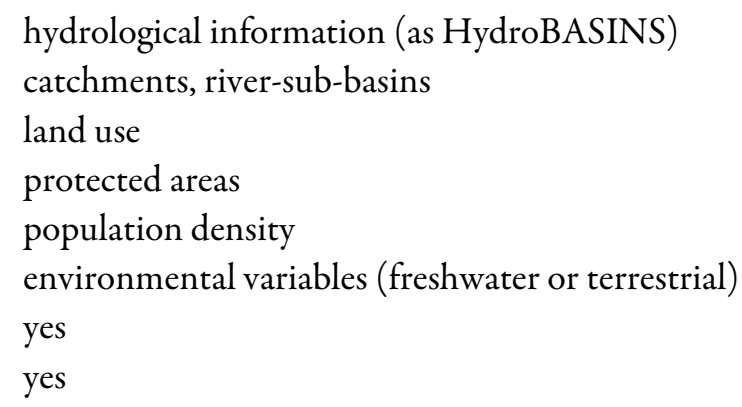

$\begin{array}{ll}\text { availability of photos: } & \text { yes } \\ \text { availability of maps: } & \text { yes }\end{array}$

quality control procedures:

quality control protocols and comments:

The quality of data resulting from water and wastewater sampling surveys included the following six major activities: (a) formulating the particular objectives of the water sampling program, (b) collecting representative water samples, (c) maintaining the integrity of the water samples through proper handling and preservation, (d) adhering to adequate chain-of-custody and 
sample identification procedures, (e) practicing quality assurance in the field by using, and (f) properly analyzing the pollutants in the water samples. These areas were equally important for insuring that environmental data are of the highest validity and quality.

\section{Acknowledgements}

This research was financially supported by the German Federal Ministry of Education and Research (BMBF project No. 033W016DN)

\section{References}

Batbayar, G., Pfeiffer, M., von Tümpling, W., Kappas, M. \& Karthe, D., 2017. Chemical water quality gradients of the sub catchments of the Mongolian Selenga River basin. Environmental Monitoring and Assessment 189: 420.

https://doi.org/10.1007/s10661-017-6123-z

Hofmann, J., Karthe, D., Ibisch, R., Schäffer, M., Kaus, A., Avlyush, S. \& Heldt, S., 2015. Initial Characterization and Water Quality Assessment of Stream Landscapes in Northern Mongolia and its Integration into a River Basin Management Plan. Water 7(7):3166-3205. https://doi.org/10.3390/w7073166

Hofmann, J., Venohr, M., Behrendt, H. \& Opitz, D., 2010. Integrated Water Resources Management in Central Asia: Nutrient and heavy metal emissions and their relevance for the Kharaa River Basin, Mongolia. Water Science and Technology 62(2):353-363. https://doi.org/10.2166/wst.2010.262

Hofmann, J., Watson, V. \& Scharaw, B., 2015. Groundwater quality under stress: contaminants in the Kharaa River basin (Mongolia). Environmental Earth Sciences 73(2): 629-648. https://doi.org/10.1007/s12665-014-3148-2

Karthe, D., Chalov, S., Moreydo, V., Pashkina, M., Romanchenko, A., Batbayar, G., Kalugin, A., Westphal, K., Malsy, M. \& Flörke, M., 2017. Assessment and prediction of runoff, water and sediment quality in the Selenga River Basin aided by a web-based geoservice. Water Resources 44(3): 399-416. https://doi.org/10.1134/S0097807817030113

Kaus, A., Schäffer, M., Karthe, D., Büttner, O., von Tümpling, W. \& Borchardt, D., 2017. Regional patterns of heavy metal concentrations in water, sediment and five consumed fish species of the Kharaa River basin, Mongolia. Regional Environmental Change 17(7): 2023-2037. https://doi.org/10.1007/s10113-016-0969-4

Malsy, M., Flörke, M. \& Borchardt, D., 2016. What drives the water quality changes in the Selenga Basin: climate change or socio-economic development? Regional Environmental Change 17(7): 1977-1989.

https://doi.org/10.1007/s10113-016-1005-4

Menzel, L., Hofmann, J. \& Ibisch, R., 2011. Untersuchung von Wasser- und Stoffflüssen als Grundlage für ein Integriertes Wasserressourcen-Management im Kharaa-Einzugsgebiet (Mongolei). Hydrologie und Wasserbewirtschaftung 55(2): 88-103.

Pfeiffer, M., Batbayar, G., Hofmann, J., Siegfried, K., Karthe, D. \& Hahn-Tomer, S., 2015. Investigating arsenic (As) occurrence and sources in ground, surface, waste and drinking water in northern Mongolia. Environmental Earth Sciences 73(2): 649-662. https://doi.org/0.1007/s12665-013-3029-0

Priess, J., Schweitzer, C., Batkhishig, O., Koschitzki, T. \& Wurbs, D., 2015. Impacts of land-use dynamics on erosion risks and water management in Northern Mongolia. Environmental Earth Sciences 73(2): 697-708.

https://doi.org/10.1007/s12665-014-3380-9.

Theuring, P., Collins, A.L. \& Rode, M., 2015. Source identification of fine-grained suspended sediment in the Kharaa River basin, northern Mongolia. Science of the Total Environment 526: 77-87.

https://doi.org/10.1016/j.scitotenv.2015.03.134 
Appendix 


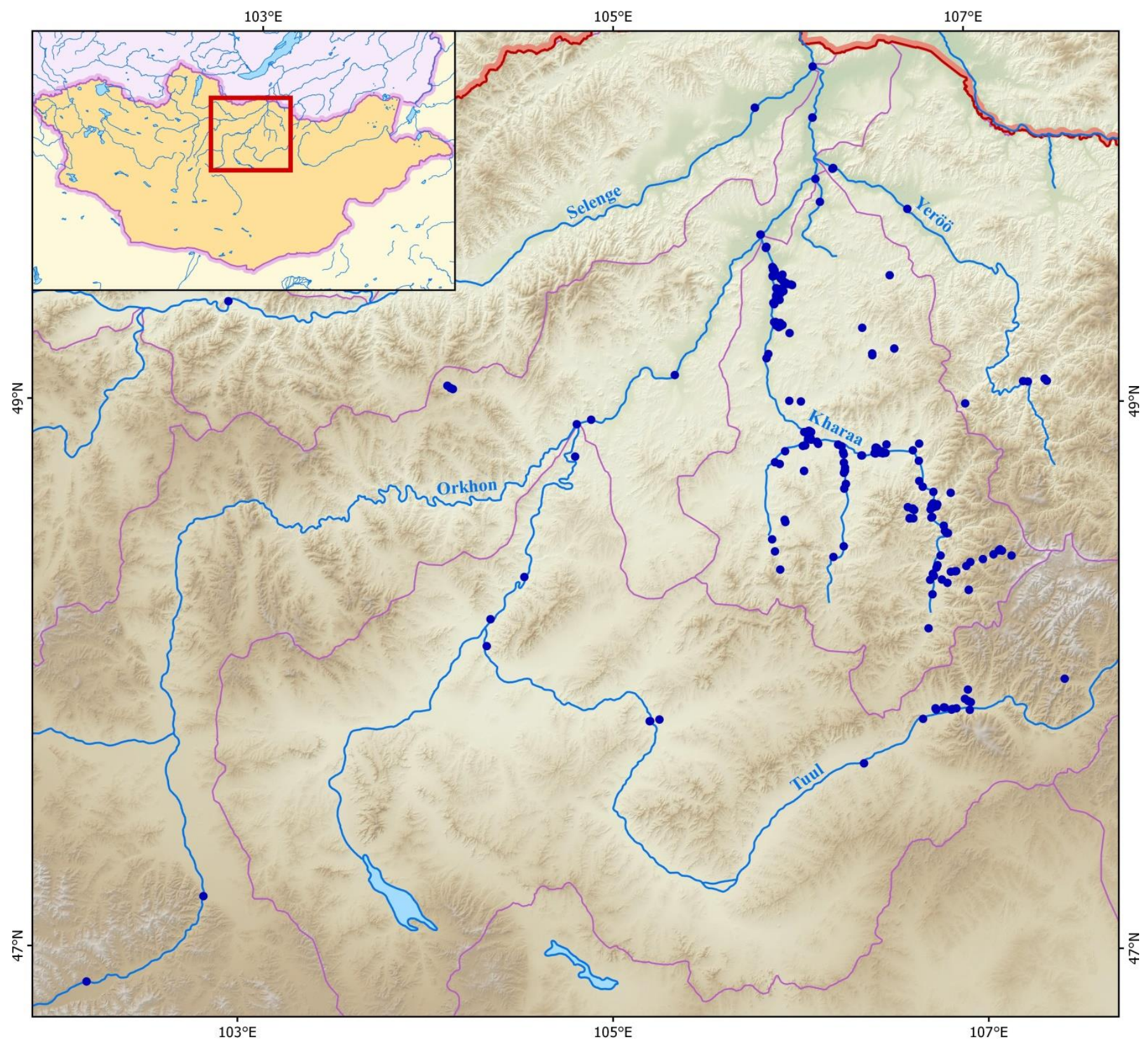

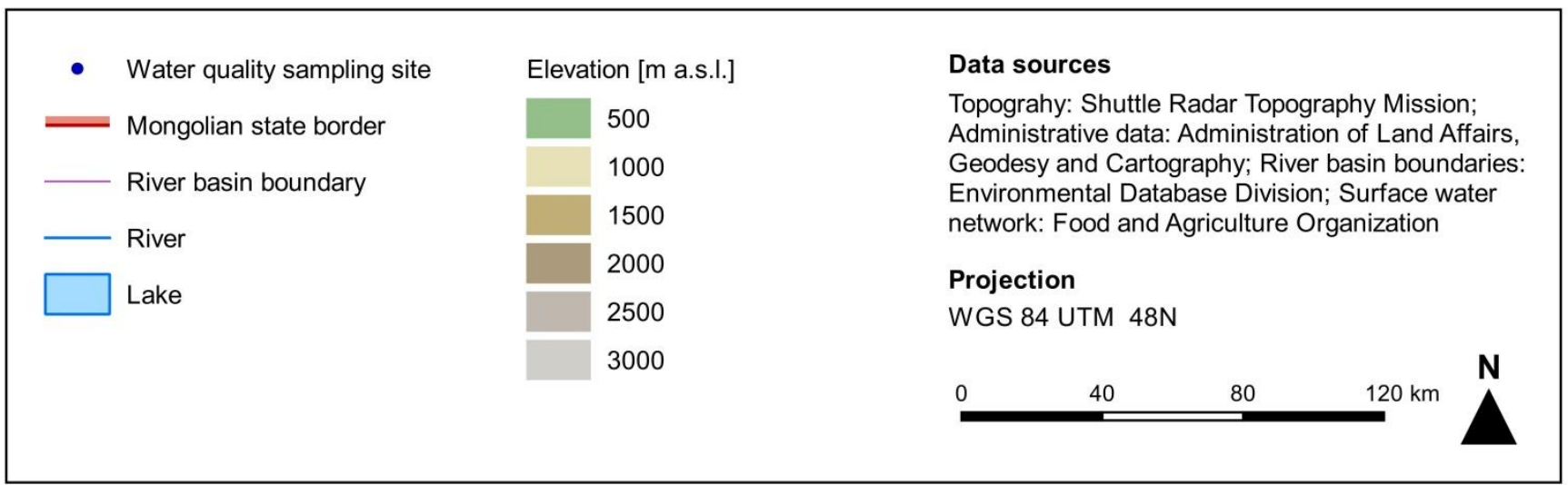

Figure 1: Spatial distribution of all measuring points and sample locations in the Kharaa Yeröö River Basin Water Quality Database 